\title{
FAGOTERAPIA FRENTE A INFECCIONES POR Staphylococcus aureus METICILINO RESISTENTE EN RATONES
}

\author{
Jesús H. Tamariz',a, Lizet Lezameta ${ }^{1, b}$ Humberto Guerra ${ }^{1, c}$
}

\author{
RESUMEN
}

Objetivos. Evaluar la actividad de los bacteriófagos frente a infecciones localizadas y sistémicas producidas por Staphylococcus aureus resistente a meticilina (MRSA) Materiales y métodos. Se realizó un estudio de tipo experimental en 45 ratones de la cepa Balb/c divididos en nueve grupos de cinco individuos. Se aislaron diez bacteriófagos nativos a partir de muestras clínicas y efluentes hospitalarios, se evaluó su capacidad lítica y su espectro de actividad, en base a lo cual se seleccionaron seis fagos para los ensayos de fagoterapia. Adicionalmente, se empleó un bacteriófago de origen comercial. La fagoterapia fue evaluada mediante profilaxis y terapia de infecciones localizadas y sistémicas causadas por la inoculación de MRSA por vía subcutánea y endovenosa respectivamente. Se probó la efectividad de tres esquemas terapéuticos: monoterapia, cóctel de fagos en múltiples dosis y de cóctel de fagos en una sola dosis. También se comparó la actividad terapéutica de los fagos frente a vancomicina y clindamicina. Resultados. El cóctel de fagos y la terapia a diversas dosis fueron efectivos para prevenir y controlar infecciones localizadas por MRSA, su actividad fue similar a la de vancomicina y clindamicina. La dosis única del cóctel de fagos no logró controlar la infección localizada; asimismo, la fagoterapia no resultó efectiva en infecciones sistémicas. Conclusiones. La fagoterapia se proyecta como una alternativa viable frente a infecciones causadas por MRSA. Se requieren estudios que evalúen aspectos relacionados con la inocuidad de los fagos frente al paciente.

Palabras clave: Bacteriófagos; Staphylococcus aureus resistente a meticilina; Ratones (fuente DeCS BIREME).

\section{PHAGOTHERAPY FACED WITH Staphylococcus aureus METHICILIN RESISTANT INFECTIONS IN MICE}

\begin{abstract}
Objectives. To assess the bacteriophage activity in localized and systemic infections caused by Staphylococcus aureus resistant to methicilin (MRSA). Materials and methods. An experimental study was performed in 45 mice of the Balb/c strain divided in nine groups of five individuals. Ten naive bacteriophages were isolated through clinical samples and hospital effluents. Lytic capacity and spectrum activity was evaluated on the basis of which six phages were selected for phagotherapy trials. Additionally, a commercial bacteriophage was used. The phagotherapy was evaluated through prophylaxis, and therapy of localized and systemic infections caused by MRSA by subcutaneous and intravenous inoculation, respectively. The effectiveness of three therapeutic schemes was tested: monotherapy, phage cocktail in multiple doses and phage cocktail in a single dose. The therapeutic activity of the phages was also compared with vancomycin and clindamycin. Results. The phage cocktail and the diverse dose therapy were effective in preventing and controlling MRSA localized infections; its activity was similar to the vancomycin and clindamycin activity. The single dose phage cocktail failed to control localized infection and phagotherapy was not effective in systemic infections. Conclusions. Phagotherapy could be a viable alternative for infections caused by MRSA. Further studies that assess related aspects to phages and patient safety are required.
\end{abstract}

Key words: Bacteriophages; Methicillin-resistant Staphylococcus aureus; Mice (source: MeSH NLM).

\section{INTRODUCCIÓN}

La resistencia a los antibióticos está llegando a niveles alarmantes. La Organización Mundial de la Salud catalogó el fenómeno como una de las amenazas más apremiantes a la salud pública en el mundo actual, considerándolo un problema crítico con severo impacto económico y social que pone en riesgo los adelantos de la medicina moderna ${ }^{(1,2)}$.

Staphylococcus aureus es uno de los patógenos humanos más importantes, se encuentra involucrado

El presente artículo se basa en la Tesis "Actividad terapéutica de bacteriófagos nativos en infecciones experimentales por Staphylococcus aureus resistente a meticilina en ratones” para optar al grado de doctor en Ciencias Biológicas presentada por Jesús Tamariz Ortiz

1 Universidad Peruana Cayetano Heredia. Lima, Perú.

aiólogo, doctor en Ciencias Biológicas; ${ }^{\mathrm{b}}$ licenciada en Tecnología Médica; ${ }^{\mathrm{c}}$ médico, doctor en Medicina

Recibido: 01-10-13 Aprobado: 08-01-14

Citar como: Tamariz JH, LezametaL, Guerra H. Fagoterapia frente a infecciones por Staphylococcus aureus meticilino resistente en ratones. Rev Peru Med Exp Salud Publica. 2014;31(1):69-77. 
en una diversidad de infecciones e intoxicaciones ${ }^{(3,4)}$ En la actualidad Staphylococcus aureus resistente a meticilina (MRSA), constituye un serio problema que se ha incrementado en el tiempo ${ }^{(1,3,5)}$. Las infecciones por MRSA dieron un dramático cambio con la aparición de los Staphylococcus aureus resistente a meticilina asociado a la comunidad (MRSA-CA), con cepas de elevada virulencia implicadas en infecciones severas de piel y partes blandas, neumonías necrotizantes graves y fulminantes ${ }^{(1,6)}$. La prevalencia de MRSA en Perú es particularmente elevada ${ }^{(7,8)}$

Lo anterior permite concluir que la solución no es la generación de nuevos antibióticos que a corto plazo se tornarán ineficaces. Es necesario ensayar otras posibilidades terapéuticas para el control efectivo del problema. Los bacteriófagos, virus que infectan exclusivamente bacterias, fueron usados a inicios del siglo pasado en el tratamiento de infecciones bacterianas. Algunos resultados controversiales provocaron que en 1934 el Council on Pharmacy and Chemistry of the American Medical Association revisara el tema y recomendara no continuar los estudios en seres humanos, ello influyó negativamente en los investigadores y las fundaciones financiadoras. En la década de los 40, el uso masivo de los antimicrobianos eliminó el interés por el tema en el mundo occidental ${ }^{(9-11)}$.

Los avances científicos actuales han mejorado el conocimiento de los fagos y dada la creciente necesidad de evaluar nuevas alternativas, distintas a los antimicrobianos convencionales, se ha renovado el interés en el estudio de sus propiedades terapéuticas ${ }^{(12-20)}$. Por ello, el objetivo del presente estudio fue evaluar la actividad de bacteriófagos nativos frente a infecciones localizadas y sistémicas producidas por MRSA empleando como modelo animal ratones y comparar su actividad frente a antimicrobianos convencionales.

\section{MATERIALES Y MÉTODOS}

\section{DISEÑO DEL ESTUDIO}

Se realizó un estudio de tipo experimental en el laboratorio y bioterio (zona de animales infectados) de los Laboratorios de Investigación y Desarrollo de la Universidad Peruana Cayetano Heredia, en el periodo 2010-2012.

\section{BACTERIÓFAGOS}

Se aislaron diez bacteriófagos a partir de muestras clínicas (hisopados nasales y faríngeos) y efluentes hospitalarios, que fueron denominados "bacteriófagos nativos". De estos, seis fagos fueron seleccionados por su mejor actividad lítica frente a MRSA (F1, F2, F7, F8, F9, F10), la combinación de estos fagos en concentraciones proporcionales fue denominada como "cóctel de bacteriófagos". El F9 mostró mayor espectro de actividad, por lo que fue elegido para la terapia individual. Adicionalmente, se evaluó un bacteriófago proveniente del Federal State Scientific Industrial Company - Microgen, Moscow Russia, nominado como bacteriófago comercial. Los bacteriófagos fueron aislados mediante pases múltiples en caldo Luria Bertani (LB), empleando como bacteria blanco una suspensión de S. aureus ATCC 25923. La presencia de bacteriófagos fue evidenciada por la formación de placas de lisis en bicapa de agar $(20 \mathrm{~mL}$ de agar TSA solidificado y $5 \mathrm{~mL}$ de agar semisólido). Las partículas virales presentes en las suspensiones fueron cuantificadas por el método de formación de placas de lisis. El detalle de estos procedimientos es descrito por Tamariz ${ }^{(21)}$.

Se determinó la morfología de los bacteriófagos aislados mediante microscopía electrónica, se empleó tinción negativa con acetato de uranilo y fosfotungstato en un Microscopio electrónico de transmisión del Centro Nacional de Microbiología del Instituto de Salud Carlos III en Madrid, España.

\section{BACTERIAS}

Para los ensayos in vivo se empleó una cepa de $S$. aureus de procedencia clínica (infección de tejidos blandos), meticilino resistente, leucocidina de PantonValentine (PVL) positivo, catalogada como MRSA-CA en un estudio previo ${ }^{(8)}$.

\section{MODELO ANIMAL}

Se emplearon ratones (Mus musculus) BALB/c, de 8 a 10 semanas, obtenidos del bioterio del Instituto Nacional de Salud del Perú. La inoculación, obtención de muestras y sacrificio de los ratones se realizaron de acuerdo a procedimientos estandarizados $(22,23)$. Previamente, se obtuvo la aprobación del proyecto por el Comité de Ética Animal de la Universidad Peruana Cayetano Heredia.

\section{EVALUACIÓN DE LA ACTIVIDAD TERAPÉUTICA EN INFECCIONES LOCALIZADAS}

Se emplearon 45 ratones divididos en nueve grupos de cinco individuos, la inoculación de bacteria y fagos fue por vía subcutánea en la región abdominal, la multiplicidad de infección (cociente entre el número de partículas virales y el número de bacterias) fue de 100. Las características de cada grupo se muestran a continuación. 
Grupo G1 (Control positivo). $6 \times 10^{7}$ unidades formadoras de colonias (ufc) de la bacteria. No recibieron tratamiento alguno. Su objetivo fue evidenciar el curso natural de la infección.

Grupo G2 (Control negativo). Bacteriófago F9, $1 \times 10^{9}$ unidades formadoras de placas (ufp). No se inoculó MRSA.

Grupo G3 (Profilaxis). 6 $\times 10^{7}$ ufc de MRSA y de inmediato y por única vez, una dosis de un cóctel de fagos (F1, F2, F7, F8, F9, F10) a una concentración de $1 \times 10^{9}$ ufp.

Grupo G4 (Tratamiento con cóctel de fagos). $6 \times 10^{7}$ ufc de MRSA. Al cuarto día de la inoculación, manifestados los síntomas, se inoculó el cóctel de fagos (F1, F4, F7, $F 8, F 9, F 10) 1 \times 10^{9}$ ufp, con dos dosis diarias durante siete días.

Grupo G5 (Tratamiento con fago nativo). $6 \times 10^{7}$ ufc de MRSA. A partir del cuarto día, presentados los síntomas, recibieron dos dosis diarias del fago $\mathrm{F} 9\left(1 \times 10^{9}\right.$ ufp), durante siete días.

Grupo G6 (Tratamiento con fago comercial). $6 \times 10^{7}$ ufc de MRSA. A partir del cuarto día, manifestados los

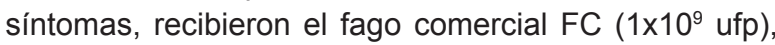
dos veces al día por siete días.

Grupo G7 (Tratamiento único con cóctel de fagos).

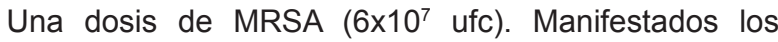
síntomas, al cuarto día, una dosis única del cóctel de fagos (F1, F2, F7, F8, F9, F10) a una concentración de $1 \times 10^{9}$ ufp.

Grupo G8 (Tratamiento con clindamicina). Se inoculó MRSA ( $6 \times 10^{7}$ ufc). A partir del cuarto día y durante siete días, recibieron dos dosis diarias de clindamicina por vía endovenosa (vena caudal), a una concentración de $20 \mu \mathrm{g}$ por g de peso del ratón (equivalente a la dosis terapéutica humana de $20 \mathrm{mg} / \mathrm{kg}$ ).

Grupo G9 (Tratamiento con vancomicina). Se inoculó MRSA ( $6 \times 10^{7}$ ufc). Manifestados los síntomas, a partir del cuarto día y durante siete días, recibieron dos dosis diarias de vancomicina por vía endovenosa, a una concentración de $15 \mu \mathrm{g}$ por g de peso del ratón (equivalente a la dosis terapéutica humana de $15 \mathrm{mg} / \mathrm{kg}$ ).

Para evaluar los resultados se consideró el diámetro de las lesiones abdominales, presencia de secreción purulenta en las lesiones, desaparición de las lesiones (cura clínica), cultivos negativos para MRSA de los hisopados de las lesiones (cura bacteriológica).

\section{EVALUACIÓN DE LA ACTIVIDAD TERAPÉUTICA EN INFECCIONES SISTÉMICAS}

Se emplearon ocho grupos de ratones de cinco individuos cada uno. Los grupos fueron similares a los considerados en las infecciones localizadas, en este caso no se consideró el grupo de clindamicina. Los ratones recibieron por vía endovenosa (vena caudal) $1 \times 10^{8}$ ufc de MRSA y $1 \times 10^{9}$ ufp de fagos, suspendidos en $100 \mu \mathrm{L}$ de suero fisiológico (multiplicidad de infección de 10).

Se emplearon como criterios de evaluación: número de ratones con síntomas de infección sistémica (decaimiento, postración, fiebre, pelaje del lomo erizado), número de ratones muertos en cada grupo. Al día 12 de la inoculación, los ratones fueron sacrificados y a partir de sus órganos se realizaron cultivos para MRSA y hemocultivos. Se consideró cura clínica la desaparición de síntomas sistémicos y cura bacteriológica cultivos negativos para MRSA en órganos y hemocultivos.

\section{ANÁLISIS ESTADÍSTICO}

Los resultados obtenidos en la terapia de infecciones localizadas fueron procesados mediante análisis de varianza: test de Anova. Para el análisis estadístico de la actividad terapéutica de los fagos en infecciones localizadas por pares de grupos experimentales se empleó la prueba de post hoc de Scheffé. El análisis se realizó mediante el paquete estadístico Stata 11.

\section{RESULTADOS}

\section{MORFOLOGÍA DE BACTERIÓFAGOS NATIVOS}

Los fagos empleados en el presente estudio correspondían a la familia Myoviridae, excepto el fago F2 que pertenecía a la familia Siphoviridae. Sus características se muestran en la Figura 1.

\section{ACTIVIDAD TERAPÉUTICA EN INFECCIONES LOCALIZADAS}

En el grupo G1 (Control positivo), las lesiones se mostraron en su máxima expresión alcanzando al día 4 un promedio de $14,4 \mathrm{~mm}$, haciéndose máximas al día 6 de la inoculación con diámetros entre 16 a 22 mm (18,2 $\mathrm{mm}$ de promedio); luego disminuyeron progresivamente (Figura 2A y 3).

En el grupo G2 (Control negativo), los cinco ratones del grupo no manifestaron ninguna lesión abdominal, ni síntomas de infección sistémica (Figura 2B y 3). 

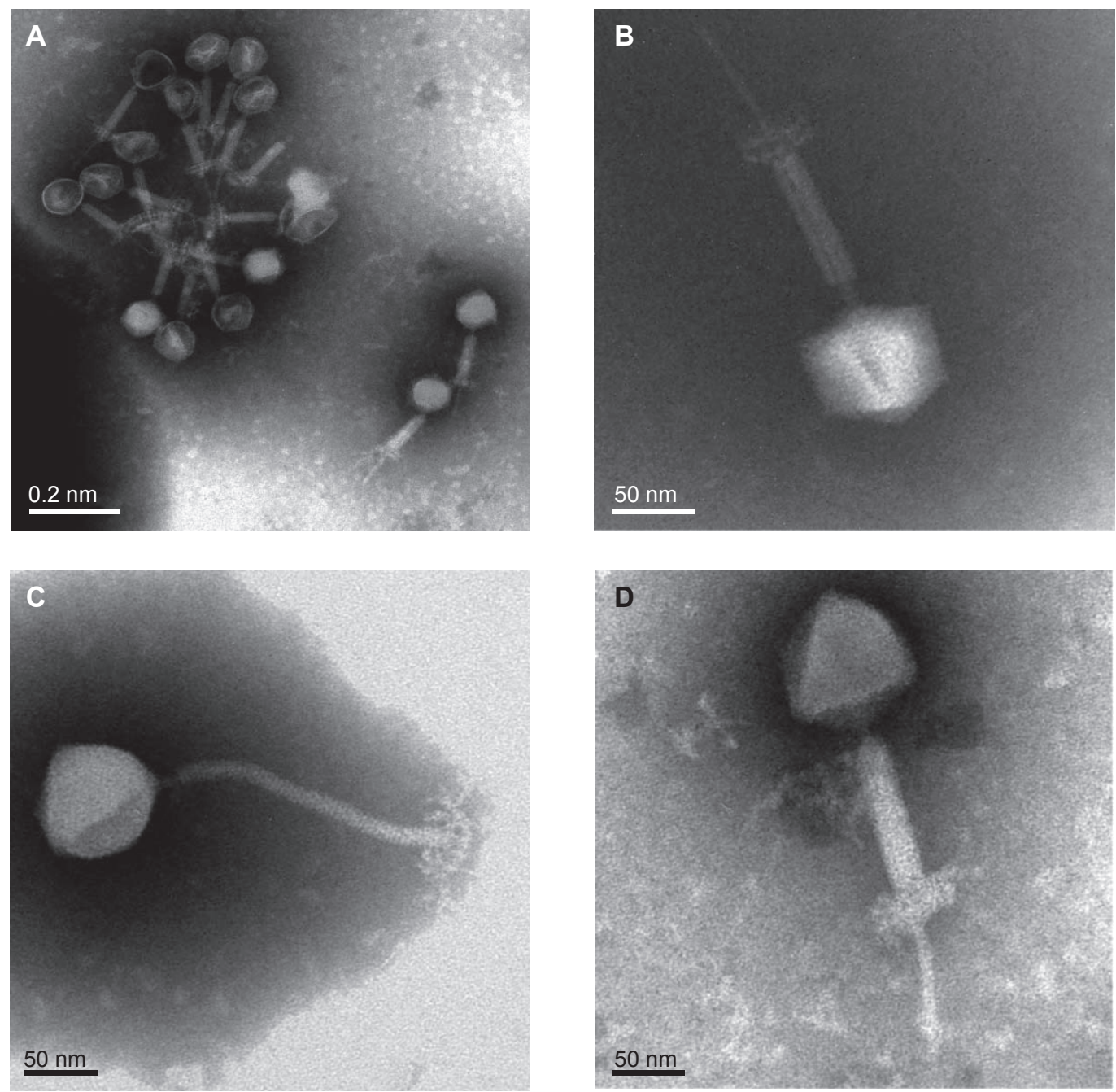

Figura 1. A. Bacteriófago comercial perteneciente a la familia Myoviridae. Se observan partículas virales caracterizadas por su cápside icosaédrica carente de envoltura vírica, simetría bilateral, cola helicoidal corta y contráctil. B. Bacteriófago nativo (F9). Partícula viral típica de la Familia Myoviridae, con cápside icosaédrica sin envoltura, cola corta y contráctil. C. Bacteriófago nativo (F2) perteneciente a la Familia Siphoviridae. Partícula viral con simetría binal, cápside icosaédrica sin envoltura y cola larga de forma helicoidal. D. Bacteriófago nativo F10. Partícula de la Familia Myoviridae, con cápside icosaédrica sin envoltura, cola corta y contráctil.

La capacidad profiláctica evaluada en el grupo G3; se evidenció por manifestación casi nula de lesiones abdominales. El análisis estadístico mostró diferencias $(p<0,0000001)$ entre el grupo $\mathrm{G} 1$ (Control positivo) y el grupo G3 (Profilaxis); Figura 2C y 3.

El tratamiento con un cóctel de fagos administrado al grupo G4, logró una elevada capacidad terapéutica (Figura 2D). Iniciada la fagoterapia las lesiones se redujeron progresivamente hasta un mínimo diámetro demostrando cura clínica (Figura 3). Los cultivos negativos mostraron cura bacteriológica. El análisis estadístico ratifica el éxito del tratamiento con una diferencia entre los resultados del grupo $\mathrm{G} 1$ y el grupo G4 $(p<0,000001)$.
La capacidad terapéutica del fago nativo F9 (grupo G5), se mostró efectiva al disminuir progresivamente las lesiones abdominales como se muestra en las Figura $2 \mathrm{E}$ y 3 . Mostrando cura clínica y bacteriológica. Un valor de $p<0,000001$, obtenido del análisis de los resultados entre los grupo $\mathrm{G} 1$ y $\mathrm{G} 5$, ratifica el éxito de la terapia.

Al evaluar los bacteriófagos de origen comercial (grupo $\mathrm{G6}$ ), estos lograron disminuir las lesiones lo que demostró de manera concluyente cura clínica y cura bacteriológica, dado que los resultados de los cultivos para MRSA fueron negativos al final del experimento en los cinco ratones. El análisis estadístico ratifica estos resultados con una diferencia entre el grupo $\mathrm{G} 1$ y $\mathrm{G} 6(p<0,000001)$. No hubo diferencia estadística con el grupo G5 (fago nativo) $(p>0,5)$. 

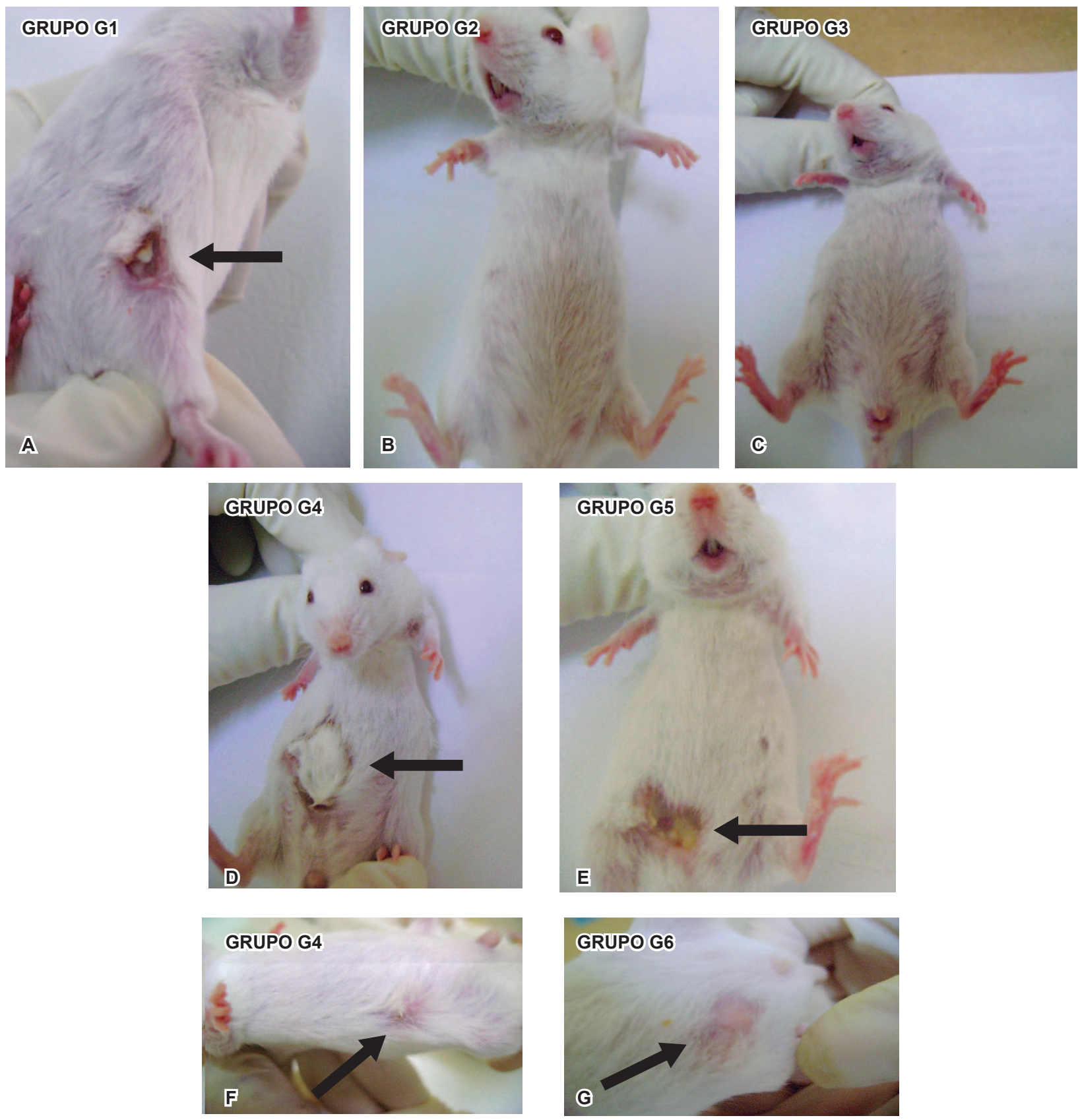

Figura 2. Resultados de la evolución clínica de la infección localizada en los grupos experimentales. A. Lesión abdominal purulenta en un ratón del grupo G1 - control positivo. B. Ratón del grupo G2 - control negativo, sin lesiones en el lugar de inoculación. C. Ratón del grupo G3 - profilaxis sin evidencia de lesión localizada. D. Lesión abdominal purulenta en un ratón del grupo G4, al 4. día de la inoculación de MRSA, antes de iniciar la fagoterapia. E. Lesión abdominal en un ratón del grupo G5 al $4 .^{\circ}$ día de la inoculación de MRSA, antes de iniciar el tratamiento con el fago nativo. F. Resultado de la fagoterapia en un ratón del grupo $\mathrm{G} 4$ al $10 .^{\circ}$ día de inoculación de MRSA, luego de 7 días de tratamiento con un coctel de fagos. G. Lesión cicatrizada en un ratón del grupo G6 luego de 10 días de inoculación de MRSA y 7 días de tratamiento con el fago Comercial, el cultivo resultó negativo.

La dosis única de tratamiento con cóctel de fagos demostró no ser suficiente. Se observó una lenta disminución de los diámetros de las lesiones, de 15,2 $\mathrm{mm}$ (rango 11-18 $\mathrm{mm}$ ) al día 4 de la inoculación, en que se aplicó por única vez un coctel de fagos hasta un diámetro promedio de 4,8 $\mathrm{mm}$ (rango $0-8 \mathrm{~mm}$ ) al día 10. Solo en un ratón la lesión mostró cura clínica, y los cultivos resultaron positivos en tres ratones, lo que evidenció cura bacteriológica solo en dos ratones (Figura 3). 


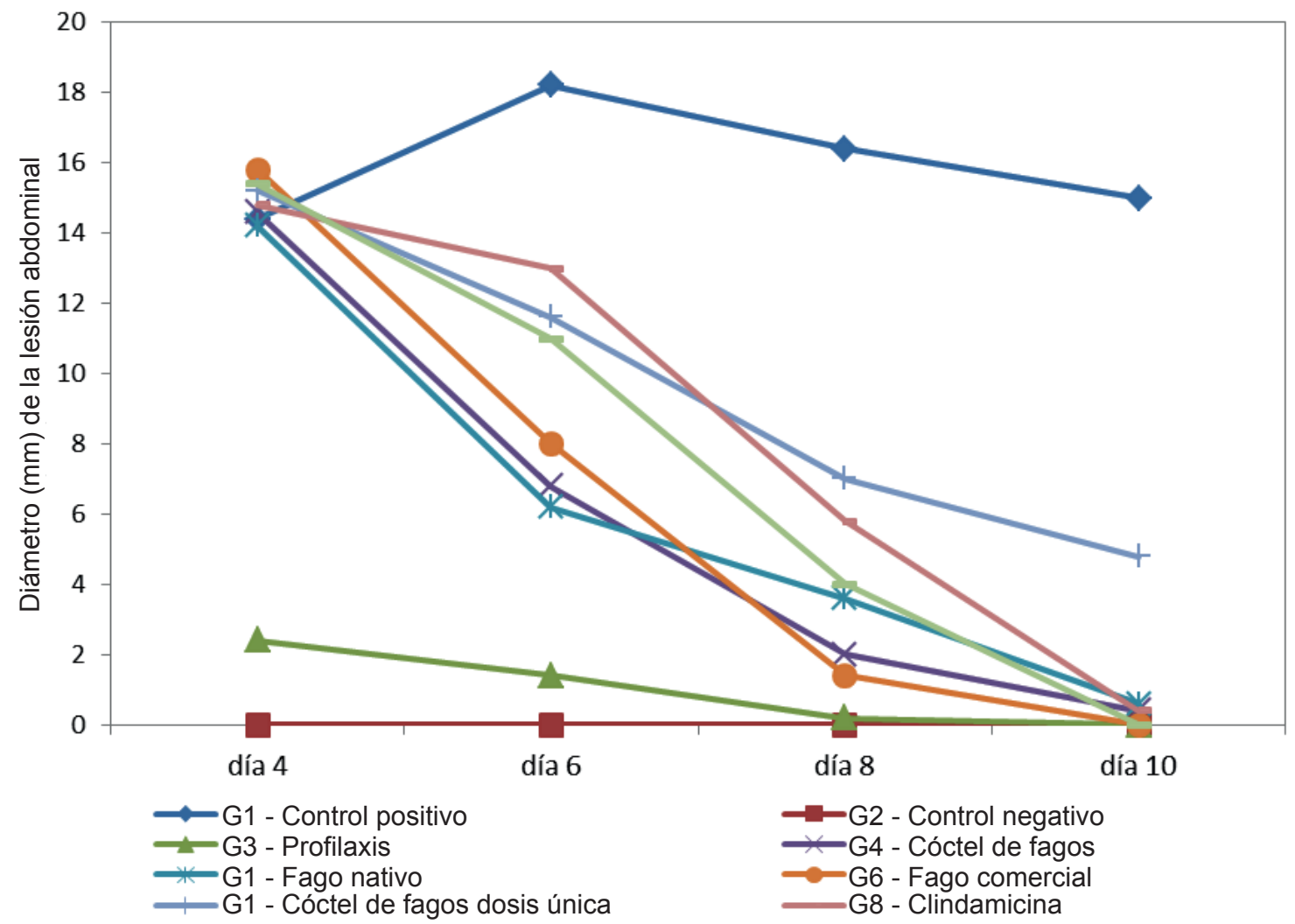

Figura 3. Evolución de las lesiones localizadas en ocho grupos de ratones

El tratamiento con antimicrobianos convencionales mostró efectividad similar a la obtenida con fagoterapia; clindamicina (grupo G8) y vancomicina (grupo G9) lograron una reducción progresiva de las lesiones, de un diámetro promedio de 14,8 al día 4 hasta 0,4 al día 10 , en el caso de clindamicina y de $15,4 \mathrm{~mm}$ al día 4 a 0,0 al día 10 con vancomicina, con cura clínica y bacteriológica en ambos casos. El análisis estadístico mostró diferencia significativa con el grupo control G1 $(p<0,00001)$. No se encontró diferencia con los grupos de fagoterapia: cóctel de fagos (G4), fago nativo (G5) y fago comercial (G6) y tampoco con el grupo de tratamiento con clindamicina (G8).

\section{ACTIVIDAD TERAPÉUTICA EN INFECCIONES SISTÉMICAS}

Los resultados de la fagoterapia sistémica en los grupos experimentales no fueron satisfactorios. No se logró cura clínica ni bacteriológica en ninguno de los grupos evaluados. En los ratones que recibieron tratamiento antimicrobiano convencional con vancomicina (grupo G9), se evidenció el éxito de la terapia. Los ratones mostraron mejoría progresiva conforme el tratamiento avanzaba. Uno de los ratones murió accidentalmente durante el tratamiento al recibir la inoculación rápida de vancomicina (antibiótico que debe ser administrado lentamente). Los hemocultivos realizados a los cuatro ratones sobrevivientes y los cultivos de órganos efectuados a los cinco ratones del grupo G8 resultaron negativos para MRSA; se mostró cura clínica y bacteriológica. Los resultados en detalle se muestran en la Tabla 1.

Tabla 1. Actividad terapéutica de bacteriófagos nativos frente a infecciones sistémicas causadas por Staphylococcus aureus meticilino resistente (MRSA)

\begin{tabular}{lccc}
\hline $\begin{array}{c}\text { Actividad } \\
\text { terapéutica }\end{array}$ & $\begin{array}{c}\text { Ratones } \\
\text { muertos/ } \\
\text { total }\end{array}$ & $\begin{array}{c}\text { Hemocul- } \\
\text { tivos posi- } \\
\text { tivos para } \\
\text { MRSA }\end{array}$ & $\begin{array}{c}\text { Cultivos de } \\
\text { organos po- } \\
\text { sitivos para } \\
\text { MRSA }\end{array}$ \\
\hline G1 (control positivo) & $2 / 5$ & $3 / 3$ & $5 / 5$ \\
G2 (control negativo) & $0 / 5$ & $0 / 5$ & $0 / 5$ \\
G3 (profilaxis) & $1 / 5$ & $2 / 4$ & $3 / 5$ \\
G4 (cóctel de fagos) & $2 / 5$ & $2 / 3$ & $3 / 5$ \\
G5 (fago nativo) & $1 / 5$ & $2 / 4$ & $4 / 5$ \\
G6 (fago comercial) & $1 / 5$ & $3 / 4$ & $3 / 5$ \\
G7 (cóctel de fagos & $2 / 5$ & $2 / 3$ & $4 / 5$ \\
en dosis única) & $1 / 5 *$ & $0 / 4$ & $0 / 5$ \\
\hline G9 (vancomicina) & $1 / 5$ & \\
\hline
\end{tabular}

* Muerte accidental de un ratón. 


\section{DISCUSIÓN}

Los resultados obtenidos en el presente estudio son positivos para el tratamiento de infecciones localizadas. Las lesiones producidas por el patógeno se vieron rápidamente controladas con la inoculación de las suspensiones del fago nativo $\mathrm{F9}$, fago comercial $\mathrm{y}$ el cóctel de fagos. La cura clínica y bacteriológica evidenciada en la totalidad de ratones tratados muestra una potente actividad terapéutica de los fagos, lo que sumado a la potente actividad profiláctica mostrada en el Grupo G3, convierten a la fagoterapia en una alternativa muy esperanzadora para tratar infecciones por MRSA.

S. aureus es uno de los patógenos humanos más importantes, está implicada en una amplia variedad de infecciones y posee elevada capacidad de generar resistencia a los antibióticos ${ }^{(8,24)}$. Los MRSA endémicos en los ambientes hospitalarios se extendieron posteriormente a la comunidad (24-26). Más recientemente el surgimiento de cepas resistentes a vancomicina, con alternativas terapéuticas restringidas a antimicrobianos de última generación, muestra un oscuro panorama que es necesario enfrentar (27). Esto orienta a la búsqueda de nuevas alternativas, diferentes a los antimicrobianos convencionales. El uso de bacteriófagos constituye una alternativa viable que cada vez va ganando mayor espacio ${ }^{(14)}$.

En nuestro estudio, el tratamiento con cóctel de fagos en múltiples dosis resultó efectivo, esta estrategia ha sido planteada por diversos autores como un enfoque alternativo y complementario para ampliar el perfil de efectividad y para contrarrestar la aparición de resistencia a los fagos durante el tratamiento ${ }^{(11,13,28,29)}$. En un entorno clínico real, la disponibilidad de cócteles de fagos brinda mayores posibilidades de tratamientos exitosos en contraste con el uso de fagos individuales, ya que no se requiere el conocimiento exacto del agente etiológico antes de iniciar el tratamiento. Este es un factor importante en situaciones de infecciones agudas en las que el tratamiento debe ser administrado lo más pronto posible; los cócteles pueden servir como una primera línea de tratamiento seguido de una correlación específica entre el fago y la bacteria patógena, si fuera necesario.

El tratamiento en dosis única con cóctel de fagos (grupo G7) no fue efectivo, pese a que diversos autores indican que es suficiente una sola dosis para controlar un proceso infeccioso ${ }^{(10,11,19,20,28-30)}$. La explicación probable a estos hallazgos es la ubicación de la infección en el modelo animal. En infecciones en el tracto digestivo, los fagos han demostrado un incremento muy rápido de la carga viral, lo que no ocurriría en las infecciones localizadas, donde la concentración de fagos es baja, por lo que serían necesarias múltiples dosis para mantener el efecto letal de los fagos ${ }^{(30)}$.

La actividad terapéutica de la clindamicina y vancomicina muestra resultados similares a los obtenidos con los fagos. Ello es muy positivo y alentador para la fagoterapia; los bacteriófagos mostraron efectividad terapéutica equivalente a los antimicrobianos más efectivos para tratar infecciones por MRSA. Una de las ventajas atribuidas a la fagoterapia es la carencia de efectos adversos ${ }^{(10,12)}$, a diferencia de lo que ocurre con los antimicrobianos en general y vancomicina en particular.

Los experimentos de fagoterapia en infecciones sistémicas no resultaron positivos pese a que se emplearon los mismos bacteriófagos y la misma cepa de MRSA. La explicación la podemos encontrar en el aclaramiento de fagos por el sistema inmune del hospedero, principalmente el sistema fagocítico mononuclear y los anticuerpos, que reducen su concentración a niveles que impiden controlar la infección bacteriana ${ }^{(10,12,14,19,28,29)}$.

Merril et al. (15) describieron una estrategia de fagos circulantes duraderos. Emplearon un procedimiento de selección natural consistente en el pasaje en serie de bacteriófagos de Escherichia coli y Salmonella enterica serotipo Typhimurium, que conduciría a la evasión de la respuesta inmune de los ratones, lo que permite mayor tiempo de permanencia de los virus en la circulación. Así mismo, Capparelli et al. (17) lograron aislar un bacteriófago lítico para Escherichia coli O157:H7, siguiendo un procedimiento similar; el fago adquirió la capacidad de persistir en el sistema circulatorio del ratón por 38 días. Estos fagos duraderos fueron capaces de controlar, en solo 48 horas, una infección sistémica de ratones infectados con E. coli O157:H7. Es probable que la obtención de "fagos duraderos" específicos para S. aureus, sean la vía para lograr el tratamiento de infecciones sistémicas causadas por MRSA.

Los resultados del estudio demuestran de manera fehaciente la capacidad de los bacteriófagos para prevenir y controlar infecciones localizadas por MRSA en la piel y tejidos blandos, lo que constituye un hallazgo muy importante que puede ser el punto de partida de posteriores investigaciones que permitan evaluar mediante ensayos clínicos, las aplicaciones terapéuticas de los bacteriófagos.

La probada efectividad de los fagos frente a MRSA, como lo muestran los resultados, ratifica el gran potencial de su aplicación en el control de bacterias multirresistentes, 
convirtiéndose en una alternativa viable y alentadora para mitigar tan serio problema. Sin embargo aún es necesario seguir investigando, ya que quedan todavía incógnitas por resolver y surgen interesantes líneas de investigación.

El uso de la fagoterapia en medicina ha tenido y tendrá importantes restricciones; sin embargo, la crisis de la antibióticoterapia convencional sumada a la diversidad de estudios que evidencian su efectividad y seguridad (10,11,30), constituyen elementos determinantes para generar líneas de investigación en este aspecto.

Es improbable que los bacteriófagos puedan sustituir totalmente a los antimicrobianos convencionales, pero se espera que puedan complementar la actividad de los mejores antibióticos (aquellos más efectivos, con menos efectos adversos, con costos más asequibles) en el tratamiento de las infecciones bacterianas resistentes a múltiples fármacos que amenazan con llevarnos la era posantibiótica.

La fagoterapia posee aún limitaciones para su aplicación; entre estas podemos citar la posibilidad de transmisión horizontal de genes de virulencia o de resistencia a antimicrobianos, la aparición de resistencia de las bacterias a la infección por los fagos, su aclaramiento del torrente sanguíneo por el sistema fagocítico mononuclear, lo que sumado a la presencia de anticuerpos neutralizantes impedirían la acción de los fagos a nivel sistémico. Existe también la posibilidad de reacciones inmunes adversas ante inoculaciones consecutivas de bacteriófagos. Estos aspectos no fueron evaluados en el presente estudio y requieren posteriores investigaciones que permitan aclarar asuntos aún controversiales en fagoterapia. Los avances en biología molecular e inmunología brindan en la actualidad herramientas que permitirán dilucidar las limitaciones del presente estudio.

Concluimos que la aplicación de cóctel de bacteriófagos y monoterapia a diversas dosis resultó efectiva para la prevención y el tratamiento de infecciones localizadas por MRSA. No se demostró actividad terapéutica ni profiláctica efectiva frente a infecciones sistémicas causadas por MRSA. De esta manera, la fagoterapia se proyecta como una alternativa que podría ser viable frente a infecciones causadas por MRSA; sin embargo, se requieren estudios que evalúen aspectos relacionados con la inocuidad de los fagos frente al paciente.

Contribuciones de autoría: JT Y HG participaron en la concepción y diseño del estudio, JT y HG obtuvieron el financiamiento. JT y LL participaron en la recolección y obtención de resultados, JT en el análisis y redacción del artículo, HG participó en la revisión crítica del artículo y aprobación de la versión final.

Fuentes de financiamiento: el proyecto fue financiado por el Fondo de Apoyo a la Investigación de la Facultad de Medicina de la Universidad Peruana Cayetano Heredia.

Conflictos de interés: los autores declaran no tener conflictos de interés.

\section{REFERENCIAS BIBLIOGRÁFICAS}

1. Tenover FC, McDougal LK, Goering RV, Killgore G, Projan SJ, Patel JB, et al. Characterization of a strain of community-associated methicillinresistant Staphylococcus aureus widely disseminated in the United States. J Clin Microbiol. 2006;44(1):108-18.

2. World Health Organization. Antimicrobial resistance: Key Facts [Internet]. Ginebra: WHO; c2013 [Updated May 2013; citado el 25 de junio del 2013]. Disponible en: http:// www.who.int/mediacentre/factsheets/ fs194/en/index.html.

3. Doebbeling BN, Breneman DL, Neu HC, Aly R, Yangco BG, Holley HP $\mathrm{Jr}$, et al. Elimination of Staphylococcus aureus nasal carriage in health care workers: analysis of six clinical trials with calcium mupirocin oitment. The
Mupirocin collaborative study group. Clin Infect Dis. 1993;17(3):466-74.

4. Archer GL. Staphylococcus aureus: a well-armed pathogen. Clin Infect Dis. 1998;26(5):1179-81.

5. Cosgrove SE, Sakoulas G, Perencevich EN, Schwaber MJ, Karchmer AW, Carmeli Y. Comparison of mortality associated with methicillinresistant and methicillin-susceptible Staphylococcus aureus bacteremia: a meta-analysis. Clin Infect Dis. 2003;36(1):53-9.

6. Boubaker K, Diebold P, Blanc DS, Vandenesch F, Praz G, Dupuis G, et al. Panton-valentine leucocidin and staphyloccoccal skin infections in schoolchildren. Emerg Infect Dis, 2004;10(1):121-4.
7. Echevarría Zarate J, Iglesias Quilca D. Estafilococo Meticilino resistente, un problema actual en la emergencia de resistencia entre los Gram positivos. Rev Med Hered. 2003;14(4):195-203.

8. Tamariz J, Agapito J, Horna J, Tapia E, Vicente W, Silva M, et al. Staphylococcus aureus resistente a meticilina adquirido en la comunidad aislados en tres hospitales de Lima-Perú. Rev Med Hered. 2010;21(1):4-10.

9. Hankin ME. The bactericidal action of the waters of the Jamuna and Ganges rivers on Cholera microbes. Ann Inst Pasteur. 1896;10:511-23.

10. Carlton RM. Phage therapy: past history and future prospects. Arch Immunol Ther Exp (Warsz). 1999; 47(5):267-74. 
11. Abedon ST, Kuhl SJ, Blasdel BG, Kutter EM. Phage treatment of human infections. Bacteriophage. 2011;1(2):66-85.

12. Loc-Carrillo C; Abedon ST. Pros and cons of phage therapy. Bacteriophage. 2011;1(2):111-4.

13. Haq IU, Chaudhry WN, Akhtar MN, Andleeb S, Qadri I. Bacteriophages and their implications on future biotechnology: a review. Virol J. 2012;9:9. doi: 10.1186/1743-422X-99.

14. Ackermann HW. Who went into phage research? Bacteriophage. 2012;2(1):55-9.

15. Merril CR, Biswas B, Carlton R, Jensen NC, Creed GJ, Zullo S, et al. Long-circulating bacteriophage as antibacterial agents. Proc Natl Acad Sci U S A. 1996;93(8):3188-92.

16. Wills QF, Kerrigan C, Soothill JS. Experimental bacteriophage protection against Staphylococcus aureus abscesses in a rabbit model. Antimicrob Agents Chemother. 2005;49(3):1220-1.

17. Capparelli R, Ventimiglia I, Roperto S, Fenizia D, Iannelli D. Selection of an Escherichia coli O157:H7 bacteriophage for persistence in the circulatory system of mice infected experimentally. Clin Microbiol Infect. 2006;12(3):248-53.

18. Capparelli R, Parlato M, Borriello G, Salvatore P, Iannelli D. Experimental phage therapy against Staphylococcus aureus in mice. Antimicrob Agents Chemother. 2007;51(8):2765-73.

19. Hanlon GW, Bacteriophages: an appraisal of their role in the treatment of bacterial infections. Int J Antimicrob Agents. 2007;30(2):118-28.

20. Ahmed K, Kaderbhai N, Kaderbhai M. Bacteriophage therapy revisited. Afr J Microbiol Res. 2012;6(14):3366-79.

21. Tamariz J, Actividad terapéutica de bacteriófagos nativos en infecciones experimentales por Staphylococcus aureus resistente a meticilina en ratones [Tesis para optar al grado académico de Doctor en Ciencias Biológicas]. Lima, Perú: Universidad Nacional Mayor de San Marcos; 2013.

22. Sociedad Española para las Ciencias del Animal de Laboratorio (SECAL). Recomendaciones para la Eutanasia de los Animales de Experimentación: Parte I. Laboratory Animals. Madrid: SECAL; 1996.

23. Sociedad Española para las Ciencias del Animal de Laboratorio (SECAL) Recomendaciones para la Eutanasia de los Animales de Experimentación: Parte II. Laboratory Animals. Madrid: SECAL; 1997.

24. Diep BA, Sensabaugh GF, Somboonna N, Carleton HA, Perdreau-Remington F. Widespread skin and soft-tissue infections due to two methicillinresistant Staphylococcus aureus strains harboring the genes for Panton Valentine leucocidin. J Clin Microbiol. 2004; 42(5):2080-4.

25. Climo MW, Patron RL, Archer GL. Combinations of vancomycin and beta -lactams are synergistic against staphylococci with reduced susceptibilities to vancomycin. Antimicrob Agents Chemother. 1999;43(7):1747-53.
26. Gillet Y, Issartel B, Vanhems P, Fournet JC, Lina G, Bes M. Association between Staphylococcus aureus strains carrying gene for Panton - Valentine Leucocidin and hightly lethal necroting pneumonia in young immunocomponent patients. Lancet. 2002;359(9308):753-9.

27. Hiramatsu K, Aritaka N, Hanaki H, Kawasaki S, Hosoda Y, Hori $S$, et al. Dissemination in Japanese hospitals of strains of Staphylococcus aureus heterogeneously resistant to vancomycin. Lancet. 1997;350(9092):1670-3.

28. Sulakvelidze A, Alavidze Z, Morris JG Jr. Bacteriophage therapy. Antimicrob Agents Chemother. 2001;45(3):649-59.

29. Gill JJ, Pacan JC, Carson ME, Leslie KE, Griffiths MW, Sabour PM. Efficacy and pharmacokinetics of bacteriophage therapy in treatment of subclinical Staphylococcus aureus mastitis in lactating dairy cattle. Antimicrob Agents Chemother. 2006;50(9):2912-8.

30. Stokowski L. The Bacteriophage Comes of Age: The Bacteriophage: Too Good to Be True? [Internet]. New York: Medscape, Infectious Diseases; 2012 [citado el 15 de mayo del 2013]. Disponible en: http://www.medscape. com $/$ viewarticle $/ 759866$ ? $\mathrm{src}=\mathrm{mp} \& \mathrm{sp}$ on $=38$

Correspondencia: Jesús Tamariz Ortiz

Dirección: Calle Juana García 160. San Miguel - Lima, Perú

Teléfono: 3190000 - Anexo 2326

Correoelectrónico:jesus.tamariz@upch.pe

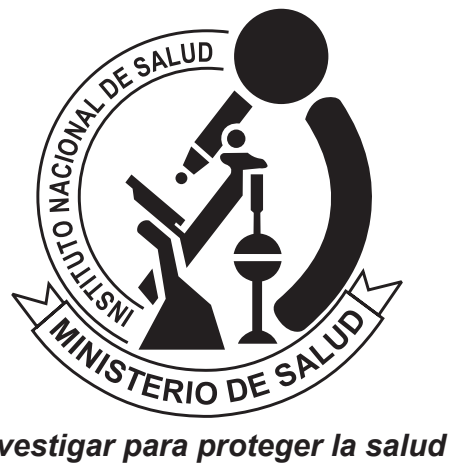

\section{Visite los contenidos de la revista en: www.ins.gob.pe/rpmesp}

